\title{
Myogenic differentiation of primary myoblasts and mesenchymal stromal cells under serum-free conditions on PCL- collagen I-nanoscaffolds
}

Aijia Cai ${ }^{1 *}$ D, Moritz Hardt ${ }^{1}$, Paul Schneider ${ }^{1}$, Rafael Schmid ${ }^{1}$, Claudia Lange ${ }^{2}$, Dirk Dippold ${ }^{3}$, Dirk W. Schubert ${ }^{3}$, Anja M. Boos' ${ }^{1}$ Annika Weigand ${ }^{1}$, Andreas Arkudas ${ }^{1}$, Raymund E. Horch ${ }^{1}$ and Justus P. Beier ${ }^{1,4}$

\begin{abstract}
Background: The creation of functional skeletal muscle via tissue engineering holds great promise without sacrificing healthy donor tissue. Different cell types have been investigated regarding their myogenic differentiation potential under the influence of various media supplemented with growth factors. Yet, most cell cultures include the use of animal sera, which raises safety concerns and might lead to variances in results. Electrospun nanoscaffolds represent suitable matrices for tissue engineering of skeletal muscle, combining both biocompatibility and stability. We therefore aimed to develop a serum-free myogenic differentiation medium for the co-culture of primary myoblasts (Mb) and mesenchymal stromal cells derived from the bone marrow (BMSC) and adipose tissue (ADSC) on electrospun

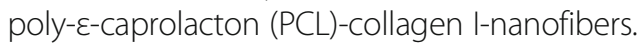

Results: Rat Mb were co-cultured with rat BMSC (BMSC/Mb) or ADSC (ADSC/Mb) two-dimensionally (2D) as monolayers or three-dimensionally (3D) on aligned PCL-collagen I-nanofibers. Differentiation media contained either AIM V, AIM V and Ultroser ${ }^{\circledast}$ G, DMEM/Ham's F12 and Ultroser ${ }^{\circledR} \mathrm{G}$, or donor horse serum (DHS) as a conventional differentiation medium. In 2D co-culture groups, highest upregulation of myogenic markers could be induced by serum-free medium containing DMEM/Ham's F12 and Ultroser ${ }^{\oplus} \mathrm{G}$ (group 3) after 7 days. Alpha actinin skeletal muscle 2 (ACTN2) was upregulated 3.3-fold for ADSC/Mb and 1.7-fold for BMSC/Mb after myogenic induction by group 3 serum-free medium when compared to stimulation with DHS. Myogenin (MYOG) was upregulated 5.2-fold in ADSC/ $\mathrm{Mb}$ and 2.1 -fold in BMSC/Mb. On PCL-collagen I-nanoscaffolds, ADSC showed a higher cell viability compared to BMSC in co-culture with Mb. Myosin heavy chain 2, ACTN2, and MYOG as late myogenic markers, showed higher gene expression after long term stimulation with DHS compared to serum-free stimulation, especially in BMSC/Mb cocultures. Immunocytochemical staining with myosin heavy chain verified the presence of a contractile apparatus under both serum free and standard differentiation conditions.

Conclusions: In this study, we were able to myogenically differentiate mesenchymal stromal cells with myoblasts on PCL-collagen I-nanoscaffolds in a serum-free medium. Our results show that this setting can be used for skeletal muscle tissue engineering, applicable to future clinical applications since no xenogenous substances were used.

Keywords: Myogenic differentiation, Nanoscaffolds, Electrospun PCL-collagen I-nanofibers, Mesenchymal stromal cells, ADSC, BMSC, Myoblasts, Serum-free media

\footnotetext{
* Correspondence: aijia.cai@uk-erlangen.de

${ }^{1}$ Department of Plastic and Hand Surgery and Laboratory for Tissue

Engineering and Regenerative Medicine, University Hospital of Erlangen,

Friedrich-Alexander University of Erlangen-Nürnberg (FAU),

Krankenhausstraße 12, 91054 Erlangen, Germany

Full list of author information is available at the end of the article
}

(c) The Author(s). 2018 Open Access This article is distributed under the terms of the Creative Commons Attribution 4.0 International License (http://creativecommons.org/licenses/by/4.0/), which permits unrestricted use, distribution, and reproduction in any medium, provided you give appropriate credit to the original author(s) and the source, provide a link to the Creative Commons license, and indicate if changes were made. The Creative Commons Public Domain Dedication waiver (http://creativecommons.org/publicdomain/zero/1.0/) applies to the data made available in this article, unless otherwise stated. 


\section{Background}

Volumetric muscle loss caused by trauma or aggressive tumor ablation is critical since it exceeds the natural regeneration capacity of skeletal muscle tissue. To reconstruct the resulting defects, donor tissue transfer, including free autologous muscle flaps, is considered as the current gold standard. This comes along with substantial donor site morbidity $[1,2]$. Three-dimensional (3D) skeletal muscle tissue constructs created via tissue engineering hold promise for treating such volumetric defects, without sacrificing a complete autologous muscle at a certain donor site [3-6].

Engineering of skeletal muscle tissue requires easily expandable cells. Current studies have investigated the co-culture of bone-marrow derived mesenchymal stromal cells (BMSC) and primary myoblasts (Mb) [7, 8]. Unlike $\mathrm{Mb}$, mesenchymal stromal cells (MSC) can be expanded widely without losing their differentiation ability. MSC are known to secrete several growth factors involved in the muscle regeneration process and to stimulate myoblast migration, proliferation, and cell survival [9].

Adipose derived stromal cells (ADSC) have gained popularity in the field of regenerative medicine because of several advantages associated with this cell type. ADSC can be obtained in abundant quantities and by minimally invasive procedures [10]. These cells can differentiate spontaneously into skeletal myoblasts, expressing myogenic markers and forming multinucleated myotubes when co-cultured with myogenic cells [11]. Tissue-engineered muscle constructs incorporating ADSC have displayed skeletal muscle regeneration potential [12].

Differentiation of $\mathrm{Mb}$ is typically induced by serum deprivation by switching from $10 \%$ fetal calf serum (FCS) to 2\% donor horse serum (DHS) [13, 14]. Yet, serum components are often considered to be inconsistent and uncharacterized, which might lead to heterogenous results due to variations in different serum lots [15]. Sera are often used from different species, which raises safety concerns. Therefore, studies have focused on the use of serum-free media [13]. Although primary cultures are more suitable for investigating in vivo skeletal muscle growth and differentiation as they represent a model that is closer to in vivo situations and clinical applications, serum-free media have only been investigated on cell lines like $\mathrm{C} 2 \mathrm{C} 12$ in terms of myogenic differentiation $[16,17]$. Yet, this is inconvenient since cell lines are inappropriate for clinical applications.

To mimic axially oriented skeletal muscle tissue, it is necessary to cultivate cells on a proper 3D matrix. For inducing multinucleated myotubes, highly aligned nanofibers generated via electrospinning seem to be the most promising scaffold $[18,19]$. Previous studies showed that pure collagen I nanofibers yielded excellent cellular affinity and myogenic differentiation of primary myoblasts seeded onto those fibers. They represented a nearly ideal scaffold for skeletal muscle tissue engineering purposes because of their similarity to the extracellular matrix. Unfortunately, they possess poor mechanical properties, leading to fast degradation and instability [20]. Composite nanofibers composed of both collagen I and the synthetic poly- $\varepsilon$-caprolactone (PCL) could overcome the obstacles stated above [21, 22].

In order to engineer transplantable skeletal muscle tissue for future translational applications, we aimed to establish a serum-free medium for myogenic differentiation of primary Mb and MSC on PCL-collagen I-nanofiber scaffolds.

\section{Results}

\section{Myoblast and ADSC characterization}

$\mathrm{Mb}$ from passage 3 and pre-plate 3 showed a $>95 \%$ positive staining for the muscle-specific marker desmin (Fig. 1). ADSC were successfully differentiated into chondrogenic, osteogenic, and adipogenic lineage (Fig. 2b-d). Furthermore, they were analyzed for cell surface markers in low (P6) and high passages (P11). Over $90 \%$ of cells were positive for CD90 $(96.9 \pm 0.98 \%$ and $95.67 \pm 4.57 \%$, respectively, $n=3)$ and CD29 (95.8 $\pm 0.66 \%$ and $94.6 \pm 5.98 \%$, respectively, $\mathrm{n}=3$ ) and negative for CD45 $(8.08 \pm 0.51 \%$ and $7.5 \pm 2.44 \%$, respectively, $n=3)$ and CD11b/c $(11.02 \pm 3.63 \%$ and $6.95 \pm$ $4.56 \%$, respectively, $n=3$ ) in both passages (Fig. 2a).

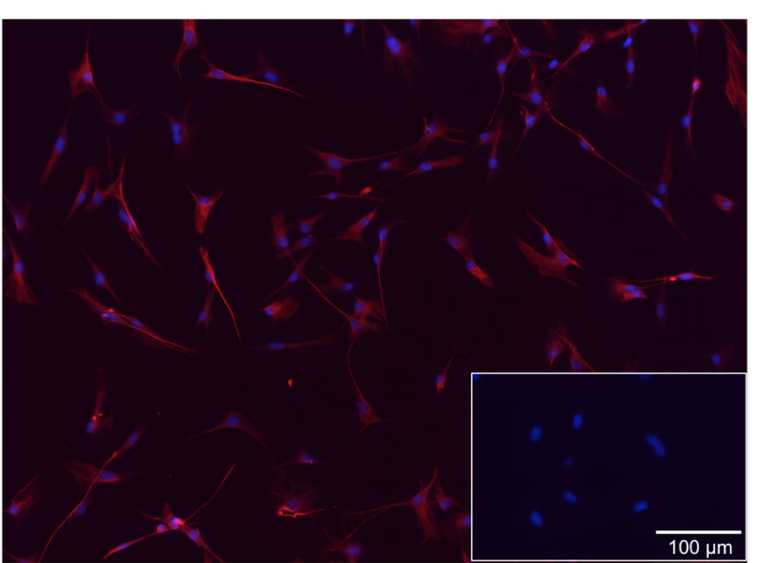

Fig. 1 Fluorescence microscopy of desmin-positive rat primary myoblasts. Myoblasts were enriched with a preplate-technique by seeding the supernatant of isolated cells into new flasks after two, 24, and $48 \mathrm{~h}$. The third preplate was further passaged until passage 3. Merge of DAPI (blue) and desmin (red, with Alexa Fluor 647 as secondary antibody) showed that nearly all cells were myoblasts (desmin-positive). Insert shows fibroblasts isolated from rat skin negative for desmin 

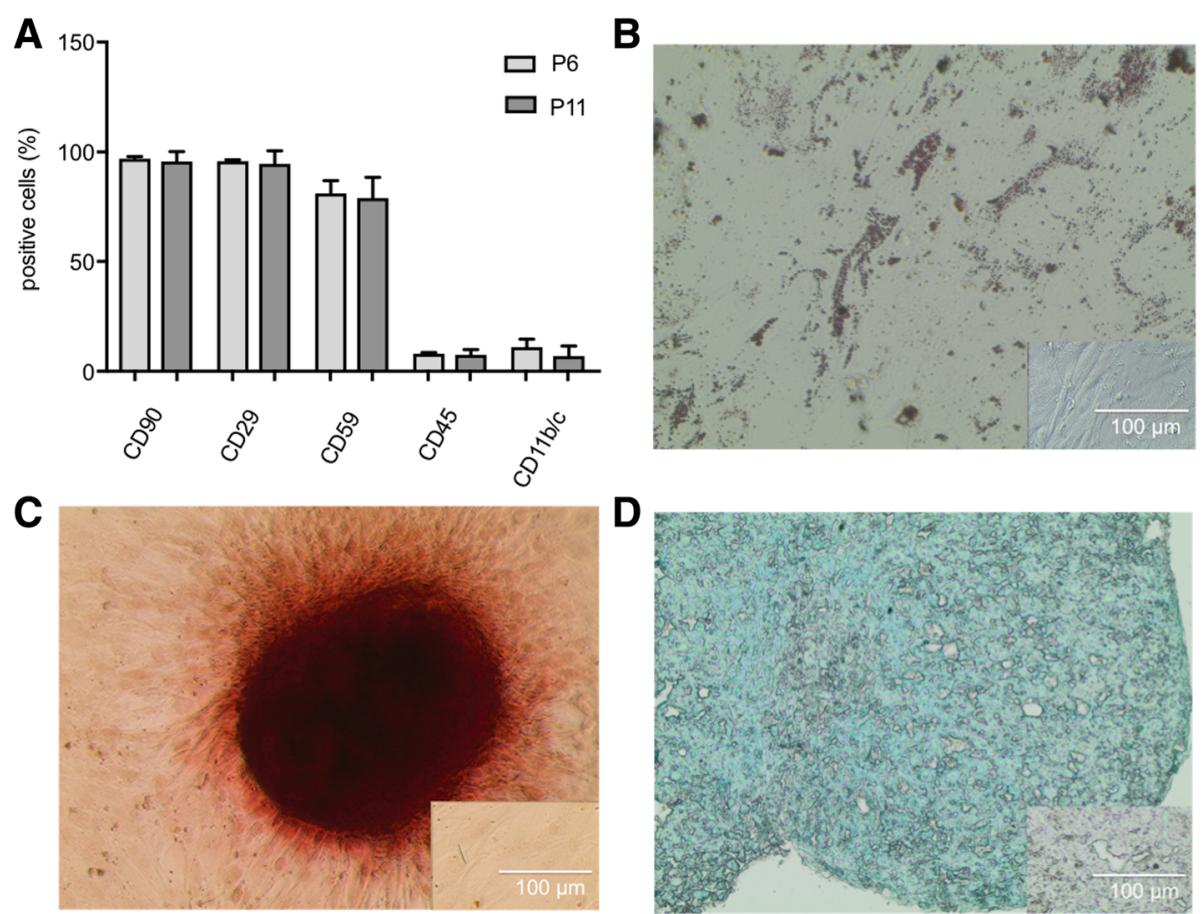

Fig. 2 Characterization of adipose derived stem cells (ADSC). a ADSC were analyzed for cell surface markers in passage 6 (P6) and passage 11 (P11). Over $90 \%$ of cells were positive for CD90 and CD29 and negative for CD45 and CD1 1b/c in both passages. Paired t-test between P6 and P11 showed no differences in expression of surface markers. ADSC in passage 4 were differentiated into adipocytes (b), osteocytes (c), and chondrocytes (d). Lipid vacuoles were visualized with oil red $\mathrm{O}$ staining (b), calcium deposits were stained with Alizarin Red S (c), and proteoglycans of chondrogenic pellets were detected by Alcian blue staining (d). Inserts represent ADSC, cultured in proliferation medium as negative controls

The effect of serum-free media on 2D mono-cultures of $\mathrm{Mb}$ and co-cultures of BMSC/Mb and ADSC/Mb

$\mathrm{Mb}$ were mono- and co-cultured with BMSC (BMSC/ $\mathrm{Mb}$ ) and ADSC (ADSC/Mb) as monolayers in differentiation media for different time periods.

After 7 days, gene expression of different myogenic markers could be observed under all conditions (Fig. 3). In $\mathrm{Mb}$, expression of ACTN2 (alpha actinin skeletal muscle 2) and $M y H C 2$ (myosin heavy chain 2) was lower under serum-free differentiation. ACTN2 was significantly downregulated after stimulation with all groups of serum-free media compared to stimulation with differentiation medium containing DHS $(p=0.0042)$. On the contrary, ACTN2 and $M y H C 2$ were both upregulated in co-culture groups. This was most noticeable in ADSC/ $\mathrm{Mb}$, though differences were not statistically significant. Group 3 led to the highest upregulation of ACTN2 and MYOG (myogenin) in ADSC/Mb. In Mb, group 1 and 2 led to an upregulation of MYOG. In BMSC/Mb, ACTN2, $M y H C 2$, and $M Y O G$ were expressed relatively similar throughout all groups.

Creatine kinase (CK) activity showed a decrease in $\mathrm{ADSC} / \mathrm{Mb}$ after 3 days of myogenic differentiation irrespective of the differentiation medium (Fig. 4). After 7 days of differentiation, CK activity further decreased in group 1 and 2 while it was stable for group 3 and slightly increased after stimulation with standard differentiation medium. Differences between groups were not statistically significant. For $\mathrm{BMSC} / \mathrm{Mb}$, results were similar with a slight decrease of CK activity in group 2 and 3 after 3 days of differentiation and a significant increase of CK activity after standard differentiation compared to group $2(p=0.048)$. After 7 days, CK activity decreased for all groups, with the strongest decrease in group 1, followed by group 2, 3, and the control group. One-way ANOVA and Bonferroni's correction for multiple comparisons showed significant differences between all groups with highly significant differences between the control group and all serum-free groups $(p<0.001)$.

\section{Cell viability on PCL-collagen I-nanoscaffolds}

Cell viability was assessed via WST-8-assay as absorbance at $450 \mathrm{~nm}$. At all time points, an increasing cell viability was noted with relation to the number of seeded cells (Fig. 5a). A trend towards an increasing cell viability was seen at 7 days for all groups, with $3 \times 10^{5}$ having the highest mean cell viability for both $\mathrm{BMSC} / \mathrm{Mb}$ as well as ADSC/Mb. Although pairwise comparison showed no significant difference, $\mathrm{ADSC} / \mathrm{Mb}$ had a higher mean cell viability than BMSC/Mb. At 14 days, ADSC/Mb showed a significantly higher cell viability for $2 \times 10^{5}$ and $3 \times 10^{5}$ cells in comparison to BMSC/Mb $(p=0.041$ and $p=0.011$, 

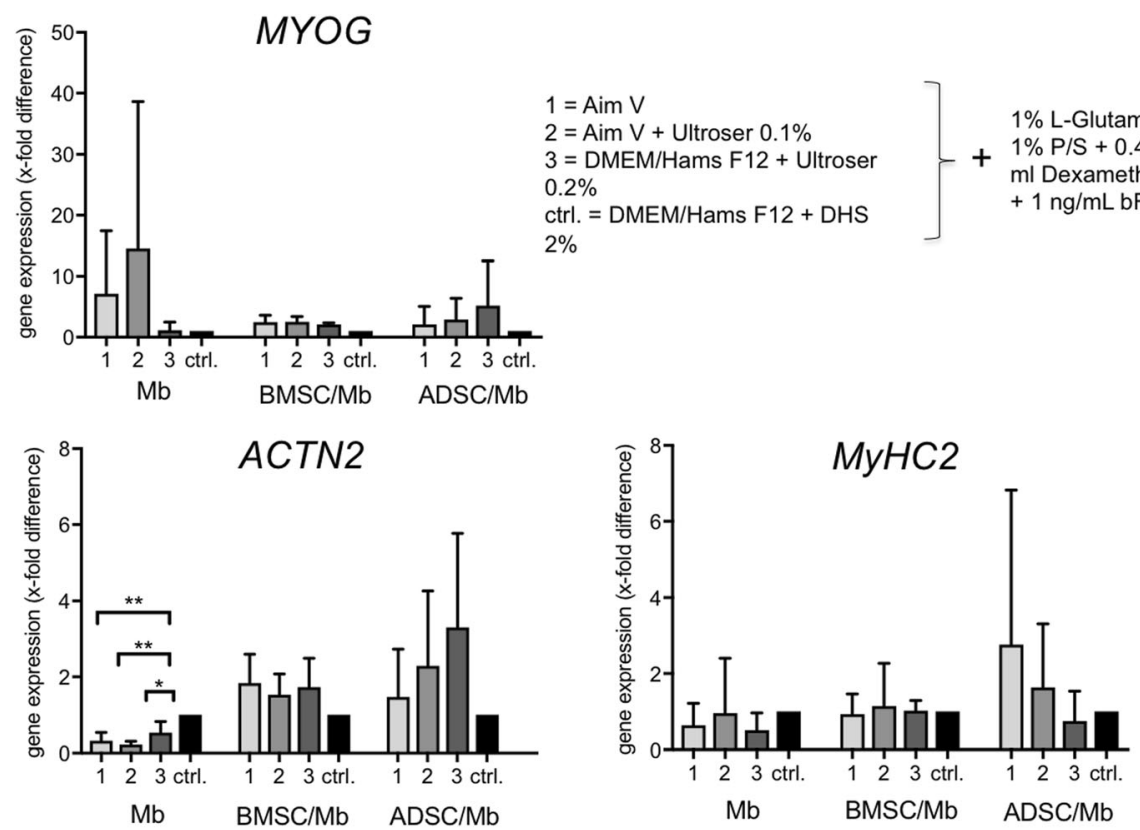

Fig. 3 Gene expression of myogenic markers in Mb, BMSC/Mb, and ADSC/Mb after serum-free myogenic differentiation. Expressions are demonstrated in $\mathrm{x}$-fold difference compared with Mb, BMSC/Mb, ADSC/Mb stimulated with standard myogenic differentiation medium ( $c$ trl. = control $=1$ ) using the $2^{-\Delta \Delta C t}$-method. Markers are presented as mean \pm standard deviation. In $\mathrm{Mb}$, serum-free differentiation led to a downregulation of ACTN2 (alpha actinin skeletal muscle 2). Statistical differences were tested with one-way ANOVA and Bonferroni's correction for multiple comparisons $(n=3)$. Levels of significance were ${ }^{*} p \leq 0.05,{ }^{* *} p \leq 0.01$

respectively). For further experiments involving myogenic differentiation of $\mathrm{ADSC} / \mathrm{Mb}$ and $\mathrm{BMSC} / \mathrm{Mb}$ on scaffolds, a total cell number of $3 \times 10^{5}$ as well as a proliferation time of 7 days were chosen due to above stated results.

WST-8-assay was repeated after 14 and 28 days of myogenic differentiation, both with and without serum (group 3) (Fig. 5b). Results showed decreased cell viability after serum free differentiation at 14 days and a further decrease at 28 days, which was significant for $\mathrm{ADSC} / \mathrm{Mb}(\mathrm{p}=0.041)$. A higher viability could be shown for $\mathrm{ADSC} / \mathrm{Mb}$ compared to $\mathrm{BMSC} / \mathrm{Mb}$ in all groups, though differences were not significant.

\section{Myogenic differentiation on PCL-collagen I-nanoscaffolds} With SEM (scanning electron microscopy) images, configuration of attached cells on PCL-collagen I-nanoscaffolds could be analyzed (Fig. 6). After 28 days of myogenic differentiation, $\mathrm{C} 2 \mathrm{C} 12$ cells showed parallel alignment on the scaffolds with myotube-like structures. ADSC/Mb were
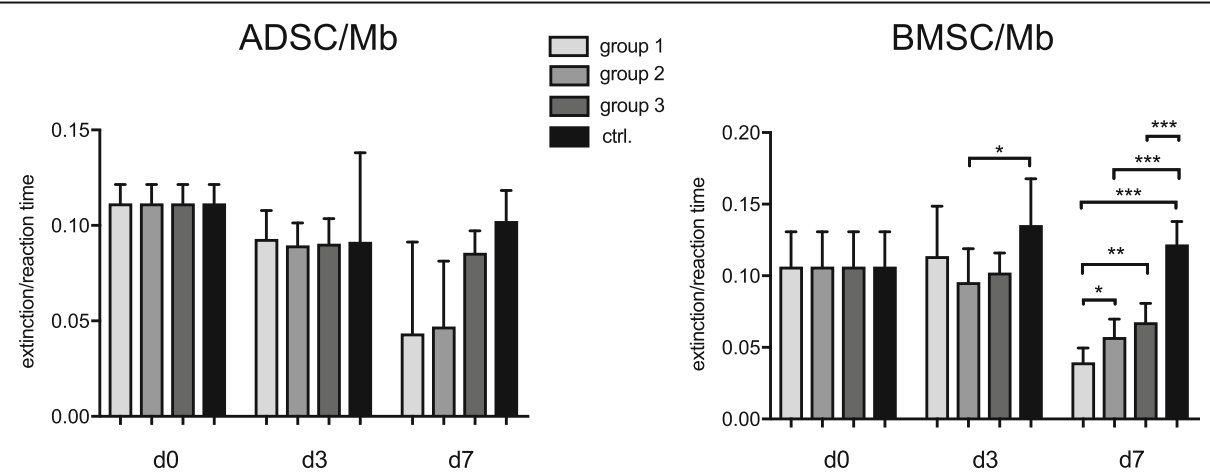

Fig. 4 CK activity of ADSC/Mb and BMSC/Mb after (serum-free) myogenic differentiation. CK activity was measured as extinction during minute 2-6 of reaction time. Cells were allowed to differentiate for three (d3) and 7 days (d7) in serum-free media group 1, 2, 3, and standard myogenic differentiation medium (ctrl.) after 2 days of proliferation (d0). Values are presented as mean \pm standard deviation. In BMSC/Mb, ctrl. Led to higher CK activity compared to all serum-free media. Highest CK activity was seen for group 3 of all serum-free media after 7 days of myogenic differentiation. Statistical differences were tested with one-way ANOVA and Bonferroni's correction for multiple comparisons $(n=3)$. Levels of significance were ${ }^{*} p \leq 0.05,{ }^{* *} p \leq 0.01,{ }^{* *} p \leq 0.001$ 

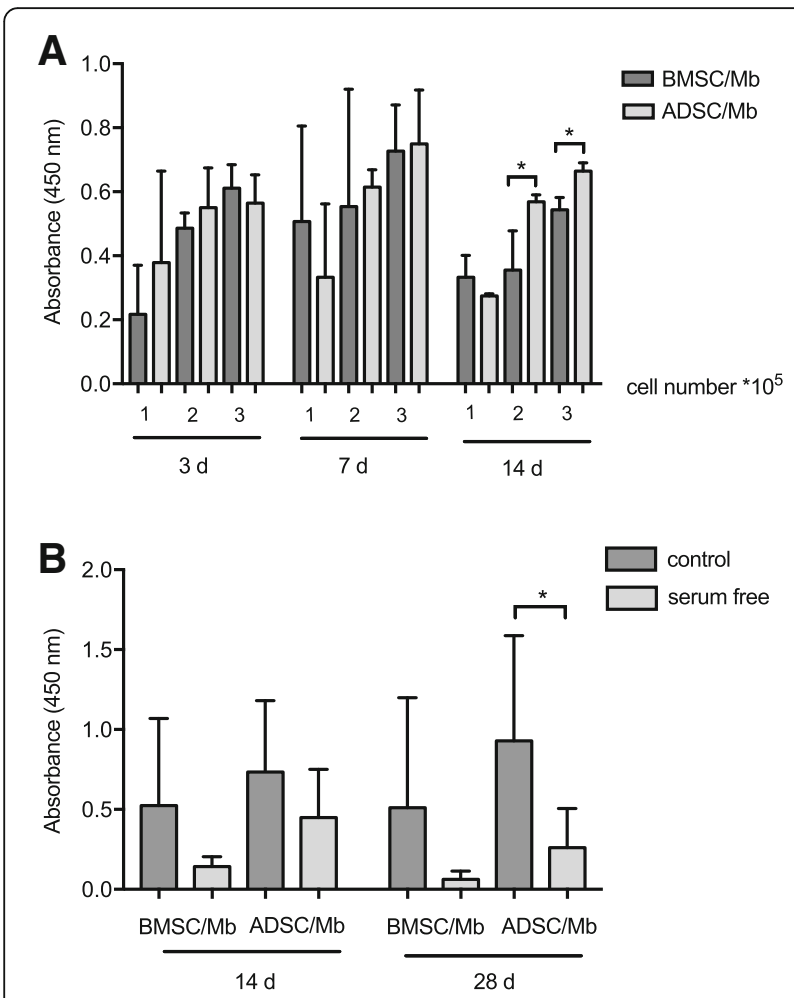

Fig. 5 Cell viability on PCL-collagen I-nanoscaffolds. a BMSC/Mb and ADSC/Mb were seeded at different densities $\left(1 \times 10^{5}, 2 \times 10^{5}, 3 \times\right.$ $10^{5}$ ) on PCL-collagen I-nanoscaffolds and were allowed to proliferate for different time periods: 3 days (d), $7 \mathrm{~d}$, or $14 \mathrm{~d}$. Cell viability was determined by WST 8-assay. Absorbance at a wave length of $450 \mathrm{~nm}$ is expressed as mean \pm standard deviation. At 14 days, ADSC showed a significantly higher cell viability for $2 \times 10^{5}$ and $3 \times 10^{5}$ cells in comparison to BMSC/Mb. b BMSC/Mb or ADSC/Mb were seeded at a density of $3 \times 10^{5}$ cells on PCL-collagen I-nanoscaffolds. Myogenic differentiation was induced by standard differentiation medium (control) or group 3 serum-free medium. WST 8-assay was repeated after 14 and 28 days of differentiation. Results showed decreased cell viability after serum free differentiation. ADSC/Mb showed higher cell viability compared to BMSC/Mb for all groups. Statistical differences were tested with repeated measures ANOVA for comparison between paired variables and Tukey's multiple comparisons test as posthoc test at different time points. Pairwise comparison between BMSC/Mb and ADSC/Mb was done using unpaired t-test $(n=3)$. Level of significance was * $p \leq 0.05$

confluent, covering almost the entire surface. BMSC/Mb were less densely spread on the scaffold.

$2 \mathrm{D}$ mono- and co-culture-groups showed rather heterogenous results in terms of gene expression of key myogenic markers. But since CK assay showed higher $\mathrm{CK}$ activity for both $\mathrm{ADSC} / \mathrm{Mb}$ and BMSC/Mb stimulated with group 3 compared to other serum-free groups, group 3 serum-free medium was chosen to be further analyzed for 3D culture on PCL-collagen I-nanoscaffolds. Gene expression of $M y H C 2$, ACTN2, and $M Y O G$ (Fig. 7) was downregulated after 28 days of serum-free myogenic differentiation for BMSC/Mb compared to controls $(p=0.0313, p=0.0137, p=0.02$, respectively). $\mathrm{C} 2 \mathrm{C} 12$, however, showed higher gene expression of $\mathrm{MyHC2}$ (2.54-fold \pm 1.86 -fold), ACTN2 (1.38-fold \pm 0.62 -fold), and MYOG (2.95-fold \pm 2.30 -fold) after serum free differentiation over the same time period, although differences were not statistically significant. For ADSC/Mb a slight trend in favor of the control group was detected.

With fluorescence microscopy, the myogenic differentiation potential of $\mathrm{BMSC} / \mathrm{Mb}$ and $\mathrm{ADSC} / \mathrm{Mb}$ seeded on PCL-collagen-nanoscaffolds was analyzed after 28 days of standard and serum free myogenic differentiation. Both control and group 3 serum-free media led to positive expression of myosin heavy chain for BMSC/Mb and ADSC/Mb. Furthermore, multinucleated cells as possible myotube formation were found (Fig. 8).

\section{Discussion}

This is, to the best of our knowledge, the first report of a serum-free medium for myogenic differentiation of primary MSC in co-culture with Mb on a biocompatible matrix.

Several studies have reported the influence of differentiation medium without serum on cell lines like $\mathrm{C} 2 \mathrm{C} 12$ or L6 [13], but the influence on co-cultures of primary $\mathrm{Mb}$ with MSC on PCL-collagen I-nanoscaffolds has not been investigated so far. The choice of serum-free media in the present study was based on promising media reported in the literature for $2 \mathrm{D}$ as well as $3 \mathrm{D}$ C2C12-culture [16, 17].

Surprisingly, CK activity decreased after induction of myogenic differentiation, although it is known to correlate with myotube formation. This could have been evoked by completely changing the growth medium into (serum free) differentiation medium. Others have suggested that a gradual decline in growth factors should rather be employed to enable cell survival and maturation into myotubes [23, 24]. Another explanation could be myotube formation with detachment from plastic surfaces in this $2 \mathrm{D}$ setting.

Electrospun PCL-collagen I-nanoscaffolds represent a biocompatible and stable matrix for 3D tissue engineering of skeletal muscle. Recently, we were able to electrospin those nanofibers, using acetic acid as a benign solvent, facilitating translational research [21]. The matrices enabled long-term differentiation of skeletal progenitor cells and parallel alignment on the nanofibers. While 2D co-cultures of BMSC/Mb and ADSC/Mb showed no expression of myosin heavy chain after 7 days (data not shown), cells expressed the myosin motor protein when seeded on the scaffolds and allowed to differentiate for 28 days. Others have described a similar time period for differentiating MSC to express key myogenic markers, especially myosin heavy chain as a late 

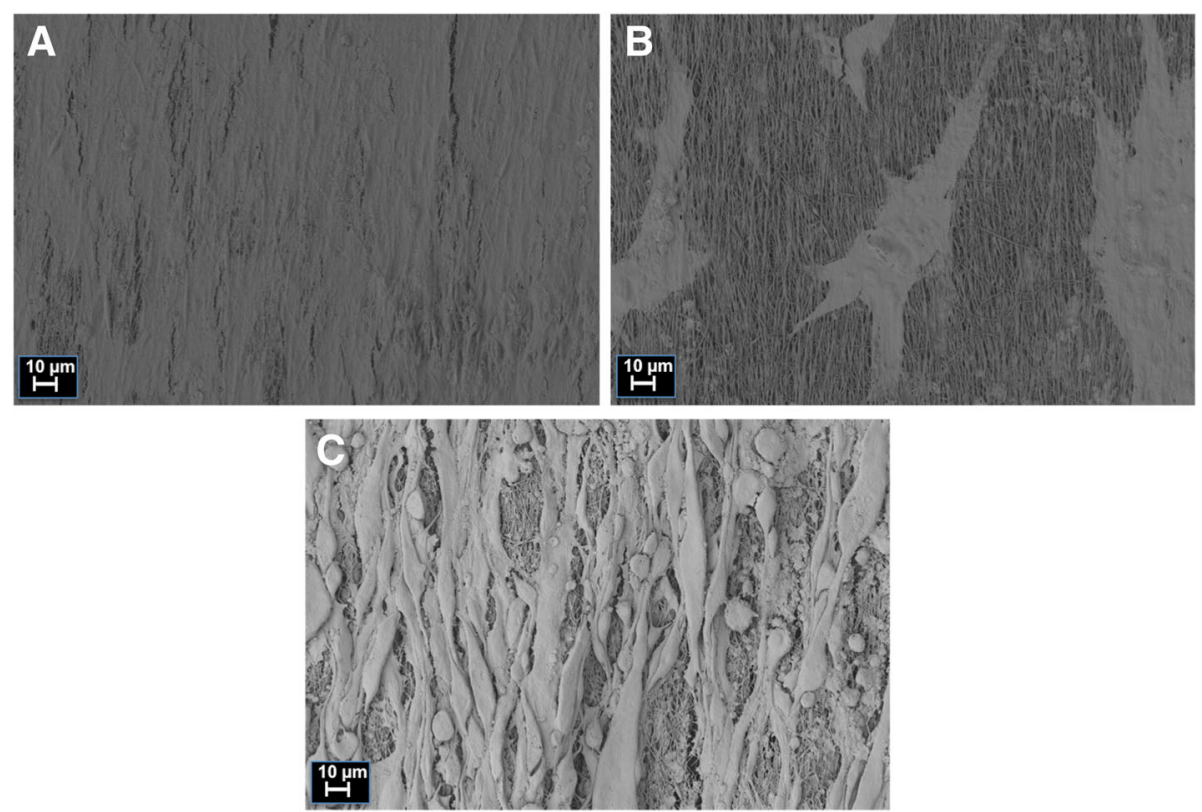

Fig. 6 Scanning electron microscopy of ADSC/Mb, BMSC/Mb, and C2C12 on PCL-collagen I-nanoscaffolds after long-term myogenic differentiation. After 28 days of myogenic differentiation, (a) ADSC/Mb were confluent, covering almost the entire surface of the scaffold. $\mathbf{b}$ BMSC/ $\mathrm{Mb}$ were less densely spread on the scaffold. c C2C12 cells showed parallel alignment on the scaffolds with myotube-like structures

myogenic marker [25-28]. Multinucleated cells, indicating possible myotube formation, could be shown under both standard and serum free differentiation conditions. This condition also led to positive gene expressions of key myogenic markers. While BMSC/Mb showed lower expression of all myogenic markers under serum free conditions, these markers were upregulated in $\mathrm{C} 2 \mathrm{C} 12$ cells up to 2.95-fold under stimulation with DMEM/ Ham's F12 and Ultroser ${ }^{\circ}$ G compared to stimulation with standard myogenic differentiation medium, containing DHS. This is in accordance to other studies [16, 17]. Ultroser ${ }^{\circ} \mathrm{G}$ contains growth factors like epidermal growth factor, transforming growth factor, insulin-like growth factor (IGF), fibroblast growth factor, insulin, thyroxine, and dexamethasone, which are also present in animal serum and are known to enhance myogenic differentiation [16, 17]. It has been shown to enhance myogenic differentiation in 3D cultures of $\mathrm{C} 2 \mathrm{C} 12$, even more than IGF [17]. More recent studies have described the utilization of the neuronal cell culture serum-free supplement B27 for myogenic differentiation of myogenic progenitors derived from human embryonic and induced pluripotent stem cells (IPS) [29]. However, the clinical application of embryonic or IPS cells might raise ethical and safety concerns. The effect of serumfree media on myogenic differentiation seems to depend on the stimulated myoblast types since the immortalized mouse cell line $\mathrm{C} 2 \mathrm{C} 12$ has shown to be enhanced in myotube formation through serum free media compared to other myoblast cells [13]. This is in accordance to the results in our study, showing that $\mathrm{C} 2 \mathrm{C} 12$ have higher expression of MYOG, ACTN2, and MHC2 after serum-free differentiation, while corresponding gene expression in co-cultures of MSC and Mb were reduced. Myogenic differentiation of MSC necessitates growth factors and direct cell contact with co-cultured myoblasts $[7,11,30]$. It might be possible that Ultroser $^{\circ} \mathrm{G}$ lacks some growth factors contained in DHS, which are crucial for myogenic differentiation of primary cells. A recent study by Sassoli et al. showed that platelet rich plasma (PRP) as a serum substitute in combination with BMSC positively influenced proliferation and differentiation of myoblasts in vitro. However, similar to animal sera, PRP's limitation is its heterogeneity due to non-standardized preparation procedures [31]. Future studies might investigate other growth factors promoting myogenic differentiation. In our study, ADSC/Mb were able to myogenically differentiate under both serum-free and standard differentiation conditions, whereas BMSC/Mb showed significant downregulation of myogenic markers after serum free differentiation. A different growth factor secretion profile could be a possible reason for this $[10,32]$. Our results are in accordance with a study published by Stern-Straeter et al., who were able to detect gene expression of myogenic markers in human ADSC after serum-free differentiation, but not in BMSC. In their study, different MSC media, unconditioned or conditioned with the supernatant of human satellite cells, were used [26]. 

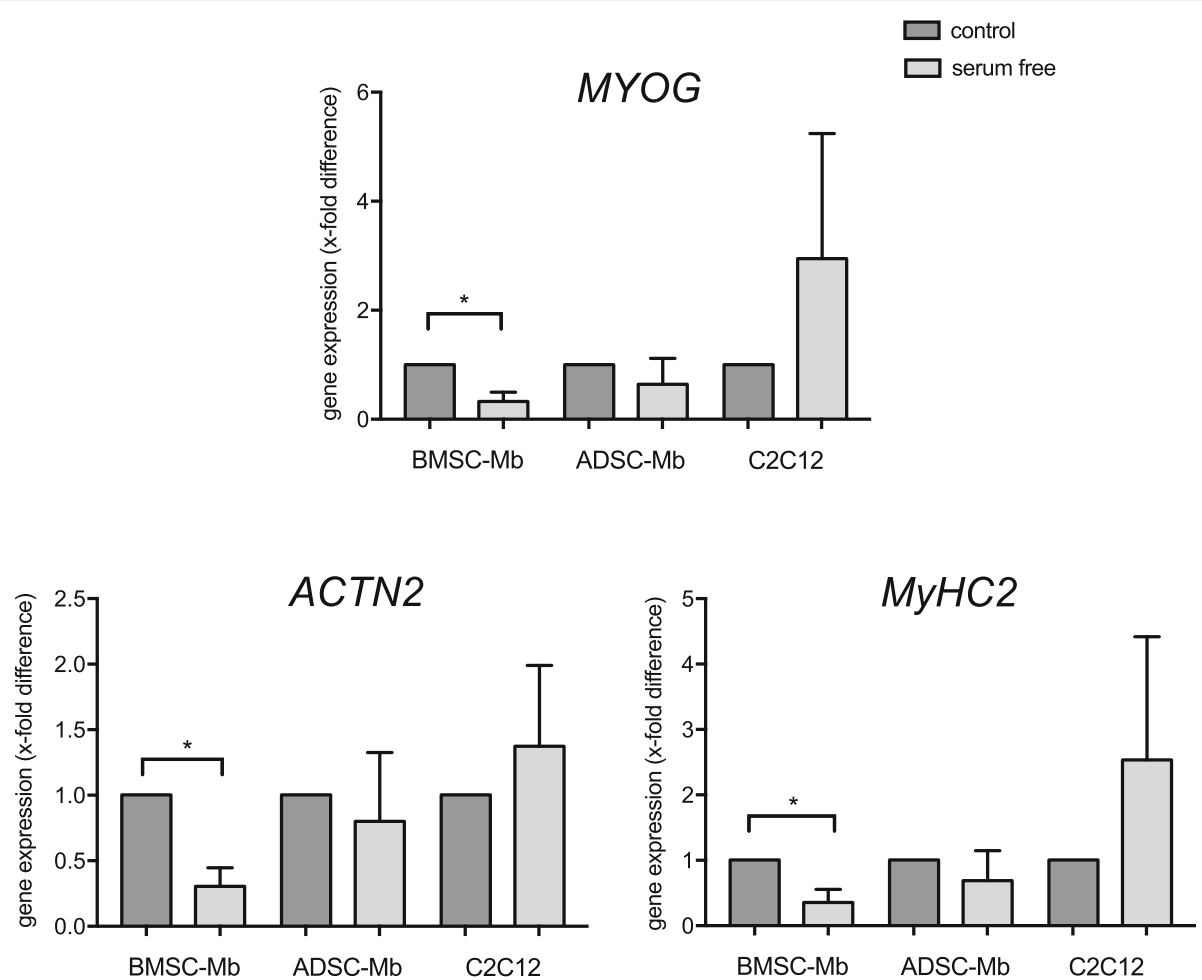

Fig. 7 Myogenic differentiation of BMSC/Mb, ADSC/Mb, and C2C12 after long-term stimulation on PCL-collagen I-nanoscaffolds. Cells were stimulated with group 3 serum-free medium. Expressions are demonstrated in $x$-fold difference compared with BMSC/Mb and ADSC/Mb, stimulated with standard myogenic differentiation medium (control $=1)$ using the $2^{-\Delta \Delta C t}$-method. Markers are presented as mean \pm standard deviation. MyHC2 (myosine heavy chain 2), ACTN2 (alpha actinin skeletal muscle 2), and MYOG (myogenin) were downregulated after 28 days of serum free myogenic differentiation for BMSC/Mb compared to controls. Statistical differences were tested with paired t-test or Wilcoxon test, as appropriate $(n=3)$. Level of significance was * $p \leq 0.05$

There are several limitations of this study. First, high standard deviations as well as small sample size, sometimes led to differences that were not statistically significant. But due to time-consuming production of PCL-collagen I-nanoscaffolds and isolation of cells, it was not possible to retrieve groups of larger sample size. Furthermore, maintaining and myogenic differentiation of primary cells isolated from adult muscle tissue is a greater challenge than culturing cell lines like $\mathrm{C} 2 \mathrm{C} 12$, which is used in a great number of other studies [13, 16, 18, 19, 33]. Since those cells do not display any contact inhibition, it is difficult to compare $\mathrm{C} 2 \mathrm{C} 12$ to primary cells. Thus, results of $\mathrm{ADSC} / \mathrm{Mb}$ and $\mathrm{BMSC} / \mathrm{Mb}$ should be evaluated independently of $\mathrm{C} 2 \mathrm{C} 12$, which should rather serve as positive control. In the past, we were able to overcome the restricted proliferation capacity of $\mathrm{Mb}$ by co-culturing them with BMSC $[7,8]$. In the present study, we successfully isolated ADSC and proved their mesenchymal stem cell characteristics to be present in high passages up to passage 11. This means that a small number of cells can be largely expanded, making this kind of cell attractive for regenerative medicine, especially in co-culture with primary myoblasts. Second, we did not distinguish between living and dead cells in our 3D setting. A live-dead assay can help to evaluate cell cytotoxicity of the scaffolds as well as clarify cell status, a potential confounding factor for myogenic differentiation. However, WST-8 assay is a commonly used tool for cytotoxicity testing since it is sensitive and reproducible [34]. The amount of formazan dye generated is directly proportional to the number of living cells and several groups have used this assay for evaluating new biomaterials or tissue engineered constructs [34-36]. WST-8-assay showed higher viability for ADSC compared to BMSC, indicating higher proliferation capacity, which has also been shown by others [37]. Third, using different culture settings (2D vs $3 \mathrm{D}$ ), we were not able to analyze expression of myogenic markers over the course of time. But, as already mentioned above, monolayered cells did not survive for a time period longer than 7 days, probably due to abrupt serum deprivation. Given the results after long term differentiation, we suppose that PCL-collagen I-nanoscaffolds serve as a platform, promoting cell survival, adhesion, and myogenic differentiation. 


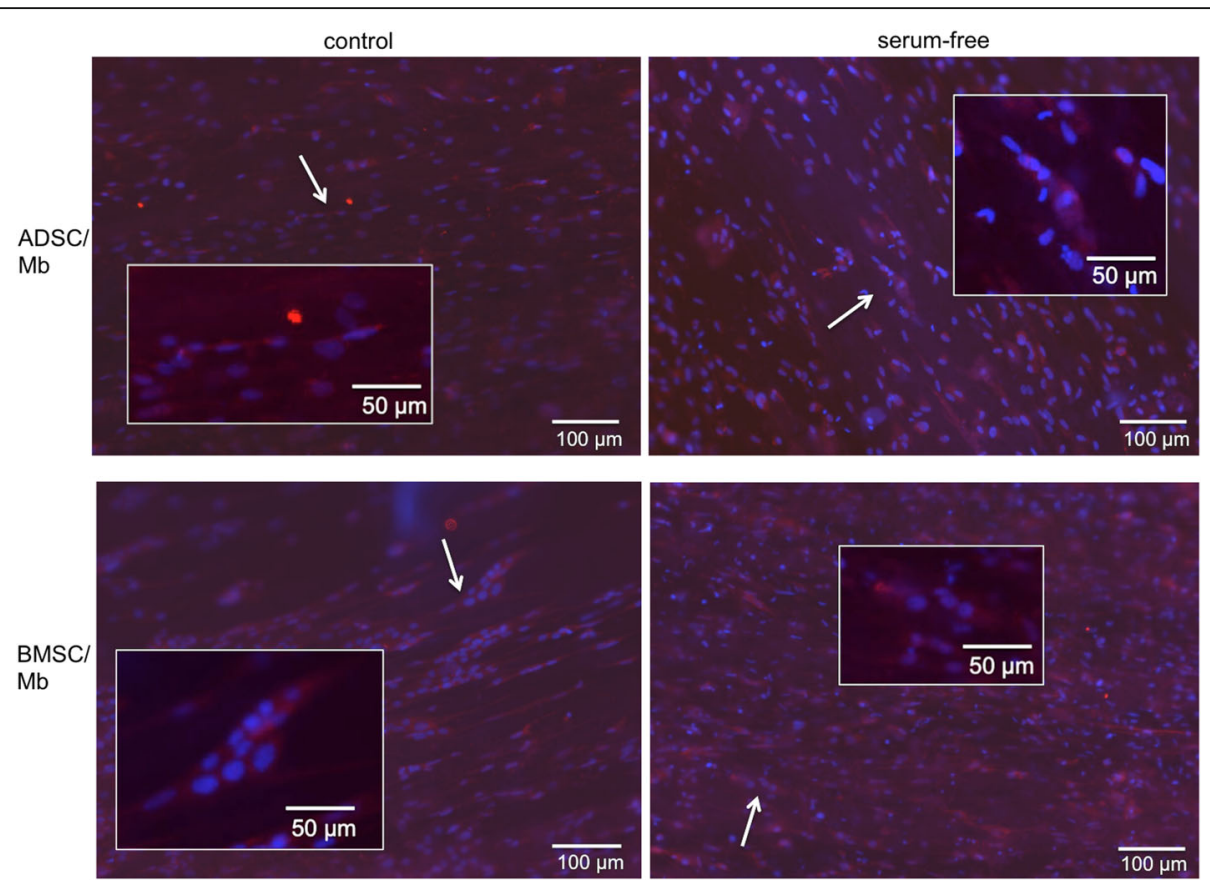

Fig. $8 \mathrm{MHC}$ expression after long-term myogenic differentiation on PCL-collagen I-nanoscaffolds. With fluorescence microscopy, the myogenic differentiation potential of BMSC/Mb and ADSC/Mb seeded on PCL-collagen I-nanoscaffolds was analyzed after 28 days of standard and group 3 serum-free myogenic differentiation. Both control and serum-free media led to positive expression of myosin heavy chain for BMSC/Mb and ADSC/Mb. Furthermore, multinucleated cells as possible myotube formation were found (representatives are marked with arrows and magnified in inserts)

\section{Conclusion}

The co-culture of ADSC and BMSC with Mb necessitates PCL-collagen I-nanoscaffolds as an adequate 3D matrix for long-term myogenic differentiation. Serum-free differentiation is feasible, particularly for ADSC/Mb. This biocompatible model for skeletal tissue engineering can be transferred to further in vivo and translational research and brought us one step closer to future clinical applications.

\section{Methods}

Myoblast cell culture

20-week old male Lewis rats (Chales River, Wilmington, Massachusetts, USA) were euthanized by cardiac exsanguination under isoflurane inhalation anaesthesia. $\mathrm{Mb}$ were isolated from hind limb muscle of male Lewis rats as described previously [8]. A preplate-technique was used for enrichment of $\mathrm{Mb}$ [38]. Briefly, cells were plated into type I collagen-coated flasks (rat tail collagen, Sigma Aldrich, St. Louis, Missouri, USA). For cell culture, Ham's F10 medium (Gibco, Carlsbad, California, USA) containing 25\% FCS (Biochrom GmbH, Berlin, Germany), 1.25\% penicillin/streptomycin (P/S) (Biochrom $\mathrm{GmbH}$ ) and $2.5 \mathrm{ng} / \mathrm{ml}$ basic fibroblast growth factor (bFGF) (Peprotech, Hamburg, Germany) was used. After 2 hours, the supernatant containing non-adherent cells was collected and replated in a new coated flask. This step was repeated every $24 \mathrm{~h}$. The third preplated cells were further passaged. Medium was changed every other day. Mb of passage 3 were used for all experiments. Desmin immunofluorescence (ab8470, Abcam, Cambridge, UK) showed a ratio of approximately $95 \%$ myoblasts (Fig. 1). Fibroblasts isolated from rat skin via dispase (Sigma Aldrich, St. Louis, Missouri, USA) and collagenase Type II (Biochrom $\mathrm{GmbH}$ ) served as negative control.

\section{BMSC and ADSC cell culture, characterization and differentiation}

Rat BMSC were isolated from the bone marrow of male Lewis rats and characterized as described previously $[39,40]$. ADSC were enzymatically isolated from the inguinal subcutaneous fat tissue of male Lewis rats. Briefly, the adipose tissue was minced and digested in $0.075 \%$ collagenase Type I (Biochrom $\mathrm{GmbH}$ ) and incubated at $5 \% \mathrm{CO} 2$ and $37{ }^{\circ} \mathrm{C}$ for $1 \mathrm{~h}$ under continuous agitation. The cell suspension was filtered through a $100 \mu \mathrm{m}$ nylon cell strainer $\left(\right.$ MACS $^{\bullet}$ SmartStrainer, Miltenyi Biotec $\mathrm{GmbH}$, Bergisch Gladbach, Germany) to remove cellular debris. After centrifugation and lysis of red blood cells the cell suspension was again filtered through a $70 \mu \mathrm{m}$ nylon cell strainer $\left(\right.$ MACS $^{\circ}$ SmartStrainer, Miltenyi Biotec $\mathrm{GmbH}$ ). The cells were resuspended in growth medium containing DMEM Ham's F12, 10\% FCS, 1\% L-Glutamin, 1\% P/S (all from Biochrom $\mathrm{GmbH}$ ). After $24 \mathrm{~h}$, the cells were washed to 
remove non-adherent cells. Phenotype was assessed by the cells' ability to differentiate into chondrocytes, adipocytes and osteocytes with specific differentiation media (Pelobiotech GmbH, Planegg, Germany). Flow cytometry was performed on cells from the 6th and 11th passage to evaluate the cell population. Cells were incubated with the following fluorochrome-conjugated antibodies: CD90, CD29, CD59, CD45, CD11b/c (Miltenyi Biotec $\mathrm{GmbH}$ ). Detection of fluorochrome labeling was performed on a fluorescence activated cell sorting cytometer (FACSCalibur) with BD CellQuest ${ }^{\mathrm{m}}$ software (BD Bioscience, Franklin Lakes, NJ, USA) and analyzed with $\mathrm{Flow}^{\circ}{ }^{\circ}$ software (Tree Star, Ashland, OR, USA). ADSC and BMSC of passage 11 were used for experiments.

\section{Differentiation conditions}

$\mathrm{Mb}$ monocultures, co-cultures of BMSC/Mb and ADSC/ $\mathrm{Mb}$ were differentiated as monolayers for 7 days. Differentiation media contained $1 \%$ L-Glutamin, $1 \% \mathrm{P} / \mathrm{S}$, $0,4 \mathrm{\mu g} / \mathrm{ml}$ dexamethasone (Sigma Aldrich), $1 \mathrm{ng} / \mathrm{ml}$ bFGF either supplemented with DMEM/Ham's F12 + 2\% DHS (Biochrom $\mathrm{GmbH}$ ) (standard serum-containing differentiation medium), AIM V (serum-free medium, Thermo Fisher Scientific Inc., Waltham, MA, USA, group 1), AIM V+0.1\% Ultroser ${ }^{\circ} \mathrm{G}$ (Cytogen $\mathrm{GmbH}$, Wetzlar, Germany) (group 2), or DMEM/Ham's F12 + $0.2 \%$ Ultroser $^{\bullet} \mathrm{G}$ (group 3) (Table 1).

For co-culture experiments, Mb/BMSC or Mb/ADSC were seeded in a ratio of 1:1 in 6-well culture plates at a density of $3 \times 10^{5}$ cells in expansion medium (DMEM/ Ham's F 12, 10\% FCS, 1\% L-Glutamin, 1\% P/S). After $48 \mathrm{~h}$, medium was replaced by differentiation medium. For $3 \mathrm{D}$ cultivation, $\mathrm{BMSC} / \mathrm{Mb}$ or $\mathrm{ADSC} / \mathrm{Mb}$ were seeded in a ratio of 1:1 at a density of $3 \times 10^{5}$ cells on PCL-collagen I-nanoscaffolds and allowed to proliferate for 7 days before differentiation was induced by group 3 serum-free medium or control medium. Medium was changed every other day. For each experiment, Mb from three different isolations were used.

\section{Electrospinning of PCL-collagen I-nanofibers and cell seeding} PCL-collagen I-nanofibers were produced by electrospinning as described previously [21]. Briefly, PCL (Sigma Aldrich) was blended with bovine collagen type I

Table 1 Myogenic differentiation media

\begin{tabular}{ll}
\hline Group & Contains 1\% L-Glutamin, 1\% P/S, \\
& $0.4 \mu \mathrm{g} / \mathrm{ml}$ Dexamethason, 1 $\mathrm{ng} / \mathrm{mL}$ bFGF + \\
\hline 1 & AIM V \\
3 & AIM V + 0.1\% Ultroser \\
standard (ctrl.) & DMEM/Ham's F12 + 0.2\% Ultroser \\
\hline
\end{tabular}

(Symatese, Lyon, France) in a ratio of 2:1 at a 10-wt.\%solution, using 90\% acetic acid (Carl Roth $\mathrm{GmbH}$, Karlsruhe, Germany) as a solvent. Electrospinning was performed on a standard electrospinning machine and parallel nanofibers were spun onto parallel metal rods on a custom made rotating drum. The aligned fibers were collected on plastic rings with $10 \mathrm{~mm}$ diameter (Minusheet carrier, Minucells and Minutissue Vertriebs GmbH, Bad Abbach, Germany). The area of the resulting scaffolds measured approximately $0,8 \mathrm{~cm}^{2}$. Scaffolds were sterilized in $70 \%$ ethanol, washed with PBS afterwards and placed into 24 well-plates while they were soaked in DMEM/Ham's F12 for approximately $1 \mathrm{~h}$ at $37{ }^{\circ} \mathrm{C}$. $\mathrm{BMSC} / \mathrm{Mb}$ or $\mathrm{ADSC} / \mathrm{Mb}$ were seeded with $100 \mu \mathrm{L}$ thickened medium containing expansion medium and dissolved methyl cellulose (Sigma Aldrich) on PCL-collagen I-nanoscaffolds at three different densities: $1 \times 10^{5}$ cells, $2 \times 10^{5}$ cells, $3 \times 10^{5}$ cells (in a ratio of 1:1, repectively). Each group was cultured in expansion medium for three, seven, and 14 days. After each time period, WST-8-assay (Promokine, Promocell $\mathrm{GmbH}$, Heidelberg, Germany) of the seeded scaffolds was performed by adding $50 \mu \mathrm{L}$ of Colorimetric Cell Viability Kit I-solution onto each scaffold. After $2 \mathrm{~h}$ of incubation, absorbance was measured at $450 \mathrm{~nm}$ with Photometer Thermo Scientific ${ }^{\mathrm{Tm}}$ Multiskan $^{\mathrm{Tm}}$ GO to assess cell viability. For the following experiments a total cell number of $3 \times 10^{5}$ cells was used with a proliferation period of 7 days prior to induction of differentiation. Differentiation was induced over a period of 28 days. WST-8-assay was repeated after 14 and 28 days of differentiation for evaluation of cell viability.

\section{RNA isolation and quantitative PCR analysis}

In $2 \mathrm{D}$ and $3 \mathrm{D}$ mono- and co-cultures the gene expression rate of $M y H C 2, A C T N 2$, and $M Y O G$ was analyzed. As housekeeping gene, $R P L 13 a$ (ribosomal protein L13a) was used. RNA of the samples was extracted using the RNeasy micro kit (Qiagen GmbH, Hilden, Germany) according to the manufacturer's protocols. RNA was reverse-transcribed into cDNA using a QuantiTect Reverse Transcription Kit and a Sensiscript Reverse Transcription Kit (both from Qiagen $\mathrm{GmbH}$ ). cDNA was amplified through quantitative real-time PCR using SsoAdvanced Universal SYBR Green PCR Supermix (Bio-Rad, Hercules, CA, USA) and Light Cycler (Bio-Rad CFX96 Touch ${ }^{\mathrm{nm}}$ ). Evaluation of gene expression was performed using the $2^{-\Delta \Delta \mathrm{Ct}}$ method. C2C12 cells (ATCC, Manassas, Virginia, USA) served as positive controls. The primer sequences used are given in Table 2.

\section{Creatine kinase activity}

$\mathrm{BMSC} / \mathrm{Mb}$ or $\mathrm{ADSC} / \mathrm{Mb}$ were seeded in a ratio of $1: 1$ at a density of $3 \times 10^{\wedge} 5$ cells in 6 -well plates as monolayers 
Table 2 Primer sequences

\begin{tabular}{lll}
\hline & Forward primer & Reverse primer \\
\hline MYOG & TGAGAGAGAAGGGAGGGAAC & ACAATACACAAAGCACTGGAA \\
MyHC2 & TGACTTCTGGCAAAATGCAG & CCAAAGCGAGAGGAGTTGTC \\
ACTN2 & TCACTGAGGCCCCTITGAAC & AGACAGCACCGCCTGAATAG \\
RPL13a & CTCATGAGGTCGGGTGGAAG & AGAGCTGCTTCTTCTTCCGG \\
\hline
\end{tabular}

and allowed to proliferate for 2 days before differentiation was induced by standard and serum-free media. CK activity was colorimetrically determined (Abcam) after 2 days of proliferation, three and 7 days of differentiation. Cells were resuspended in $50 \mu \mathrm{L}$ CK assay buffer and $5 \mu \mathrm{L}$ of the suspension was used for reaction. The reaction is based on enzymatic conversion of creatine and adenosine triphosphate into phosphocreatine and adenosine diphosphate (ADP) by CK. ADP is subsequently applied to form nicotinamide adenine dinucleotide (NADH) after reaction mix is added to each sample. The amount of NADH generated by creatine kinase was determined photometrically at $450 \mathrm{~nm}$ with Thermo Scientific $^{\text {Ta }}$ Multiskan $^{\text {Tw }}$ GO during minute 2-6 of reaction time since after $6 \mathrm{~min}$, the activity of the samples was found to have reached a plateau.

\section{Immunofluorescence}

For freshly isolated $\mathrm{Mb}$, third preplates in passage 3 were seeded on collagen-coated 48-well plates at a density of $5 \times 10^{3}$ cells. After $24 \mathrm{~h}$, cells were fixed with formaldehyde (Carl Roth $\mathrm{GmbH}$ ) and washed and incubated in blocking buffer consisting of PBS with 1.5\% FCS and 0.25\% TritonX (Carl Roth $\mathrm{GmbH}$ ) for $1 \mathrm{~h}$ at room temperature. After washing with TBS-T buffer (100 mM Tris and $\mathrm{NaCl}$ in distilled water, $1 \mathrm{ml}$ Tween 20 per $1 \mathrm{~L}$, $\mathrm{pH}$ 7.6), cells were incubated with desmin primary antibody (ab8470, Abcam) at $0.5 \mu \mathrm{g} / \mathrm{ml}$ for $1 \mathrm{~h}$.

$\mathrm{BMSC} / \mathrm{Mb}$ or $\mathrm{ADSC} / \mathrm{Mb}$ were seeded in expansion medium at a density of $3 \times 10^{\wedge} 5$ cells on PCL-collagen I-nanoscaffolds. After 7 days, the medium was switched to differentiation medium with or without serum. After 4 weeks, scaffolds were fixed, washed, and blocked as described above. For staining, scaffolds were covered with anti-fast myosin skeletal heavy chain antibody (ab91506, Abcam) diluted $5 \mu \mathrm{g} / \mathrm{ml}$ in blocking buffer for $1 \mathrm{~h}$ at room temperature.

Alexa Fluor 647 goat anti-rabbit IgG H\&L (ab150083, Abcam) was used as secondary antibody at $4 \mu \mathrm{g} / \mathrm{ml}$ for $30 \mathrm{~min}$ at room temperature for both $\mathrm{Mb}$ and co-cultures. Probes were counterstained with DAPI $1 \mu \mathrm{g} / \mathrm{ml}$ (diamidine-phenylindole-dihydrochloride, Thermofisher Scientific Inc.) for $5 \mathrm{~min}$. Cells were subsequently analyzed and digitally photographed with a fluorescence microscope (IX83, cellSens, software, Olympus, Hamburg, Germany).
$\mathrm{C} 2 \mathrm{C} 12$ and skeletal muscle slides served as positive control while fibroblasts isolated from rat skin served as negative control.

\section{Scanning electron microscopy}

$\mathrm{BMSC} / \mathrm{Mb}, \mathrm{ADSC} / \mathrm{Mb}$, or $\mathrm{C} 2 \mathrm{C} 12$ were seeded on PCL-collagen I-nanoscaffolds at a density of $3 \times 10^{5}$ cells and allowed to proliferate for 7 days bevor differentiation was induced with standard differentiation medium for 28 days. Microstructural analysis of the seeded scaffolds was performed using an Auriga Fib-SEM (Zeiss, Oberkochen, Germany) as described previously $[8,21]$. Probes were sputter-coated with gold for 1 min using an EMITECH-K550 sputter coater at an operating pressure of $7 \times 10^{2}$ bar and a deposition current of $20 \mathrm{~mA}$.

\section{Statistical analysis}

Data are expressed as mean-standard deviation. Data normality was verified by the Shapiro-Wilk test. Results were statistically interpreted by one-way analysis of variance (ANOVA) with Bonferroni's correction for multiple comparisons or Friedman test with Dunn's correction for multiple comparisons, as appropriate. Comparisons between paired variables at different time points were done using repeated measures ANOVA with Tukey's multiple comparisons test for post hoc analysis. Pairwise comparison between different co-cultures was done using unpaired t-test or Mann-Whitney test, as appropriate. Statistical analysis was performed using GraphPad Prism version 7.0a, La Jolla California USA.

A $p$-value $\leq 0.05$ was considered statistically significant.

\section{Abbreviations}

2D: Two-dimensional; 3D: Three-dimensional; ADSC: Adipose tissue derived mesenchymal stromal cells; ADSC/Mb: Adipose tissue derived mesenchymal stromal cells co-cultured with myoblasts; bFGF : Basic fibroblast growth factor; BMSC: Bone marrow derived mesenchymal stromal cells; BMSC/ $\mathrm{Mb}$ : Bone marrow derived mesenchymal stromal cells co-cultured with myoblasts; CK: Creatine kinase; DHS: Donor horse serum; FCS: Fetal calf serum; IGF: Insulin-like growth factor; Mb: Myoblasts; MSC: Mesenchymal stromal cells; PCL: Poly-e-caprolacton; P/S: Penicillin/streptomycin; PRP: Platelet rich plasma

\section{Acknowledgements \\ The present work was performed in fulfillment of the requirements for obtaining the degree "Dr. med." for MH. We would like to thank Stefan Fleischer, Marie- Louise Gorkisch and Ilse Arnold-Herberth for their excellent technical support. \\ Funding \\ This study was funded by the ELAN-Fond (15-10-07-1-Cai) of the Friedrich-Alexander University of Erlangen-Nürnberg, and the Deutsche Forschungsgemeinschaft (DFG, BE 4803/3-2). Funding was used for production of scaffolds and cell culture experiments. Furthermore, D. Dippold and R. Schmid were partially funded by DFG and the ELAN-Fond, respectively.}

\section{Availability of data and materials}

The datasets used and/or analysed during the current study are available from the corresponding author on reasonable request. 


\section{Authors' contributions}

AC designed the study, performed cell isolations analysed and interpreted the data, and was a major contributor in writing the manuscript. MH, PS, and RS performed cell culture experiments and analysed the data. MH performed cell isolations, flow cytometry, GPCR. MH and RS performed immunocytochemistry. $\mathrm{CL}$ performed BMSC isolations and characterization. DD carried out the electrospinning process and performed scanning electron miscroscopy. DWS participated in the electrospinning process. AW and AMB performed the cell isolations and cell culture experiments. AA participated in immunocytochemistry. REH participated in the cell isolations and the coordination of the study. JPB contributed to study design and interpretation of the data, participated in cell isolations and helped to draft the manuscript. All authors have seen and agreed to the final submitted version of the paper.

\section{Ethics approval and consent to participate}

Animal experiments were carried out following the German regulations for the care of laboratory animals at all times. Experiments were approved by the Animal Care Committee of the University of Erlangen and the Government of Mittelfranken, Germany (DMS-2532-2-161).

\section{Consent for publication}

Not applicable.

\section{Competing interests}

The authors declare that they have no competing interests.

\section{Publisher's Note}

Springer Nature remains neutral with regard to jurisdictional claims in published maps and institutional affiliations.

\section{Author details}

${ }^{1}$ Department of Plastic and Hand Surgery and Laboratory for Tissue Engineering and Regenerative Medicine, University Hospital of Erlangen, Friedrich-Alexander University of Erlangen-Nürnberg (FAU), Krankenhausstraße 12, 91054 Erlangen, Germany. ${ }^{2}$ Interdisciplinary Clinic for Stem Cell Transplantation, University Cancer Center Hamburg (UCCH), 20246 Hamburg, Germany. ${ }^{3}$ Institute of Polymer Materials, Department of Materials Science and Engineering, University of Erlangen-Nürnberg (FAU), Martensstraße 7, 91058 Erlangen, Germany. ${ }^{4}$ Department of Plastic Surgery, Hand Surgery, Burn Center University Hospital RWTH Aachen, Aachen, Germany.

\section{Received: 6 June 2018 Accepted: 28 October 2018}

Published online: 26 November 2018

\section{References}

1. Lee KT, Mun GH. A systematic review of functional donor-site morbidity after latissimus dorsi muscle transfer. Plast Reconstr Surg. 2014;134(2):303-14.

2. Knox AD, Ho AL, Leung L, Tashakkor AY, Lennox PA, Van Laeken N, Macadam SA. Comparison of outcomes following autologous breast reconstruction using the DIEP and Pedicled TRAM flaps: a 12-year clinical retrospective study and literature review. Plast Reconstr Surg. 2016;138(1): $16-28$.

3. Cittadella Vigodarzere G, Mantero S. Skeletal muscle tissue engineering: strategies for volumetric constructs. Front Physiol. 2014;5:362.

4. Mertens JP, Sugg KB, Lee JD, Larkin LM. Engineering muscle constructs for the creation of functional engineered musculoskeletal tissue. Regen Med. 2014;9(1):89-100.

5. Willett NJ, Krishnan L, Li MT, Guldberg RE, Warren GL. Guidelines for models of skeletal muscle injury and therapeutic assessment. Cells Tissues Organs. 2016;202(3-4):214-26.

6. Horch RE, Weigand A, Wajant H, Groll J, Boccaccini AR, Arkudas A. Biofabrication: new approaches for tissue regeneration. Handchir Mikrochir Plast Chir. 2018;50(2):93-100

7. Beier JPB, F F, Lange C, Klumpp D, Arkudas A, Bleiziffer O, Boos AM, Horch RE, Kneser U. Myogenic differentiation of mesenchymal stem cells COcultured with primary myoblasts. Cell Biol Int. 2013;35(4):397-406.

8. Witt R, Weigand A, Boos AM, Cai A, Dippold D, Boccaccini AR, Schubert DW Hardt M, Lange C, Arkudas A, et al. Mesenchymal stem cells and myoblast differentiation under HGF and IGF-1 stimulation for 3D skeletal muscle tissue engineering. BMC Cell Biol. 2017;18(1):15.
9. Okamura LH, Cordero P, Palomino J, Parraguez VH, Torres CG, Peralta OA. Myogenic differentiation potential of mesenchymal stem cells derived from fetal bovine bone marrow. Anim Biotechnol. 2018;29(1):1-11.

10. Strioga M, Viswanathan S, Darinskas A, Slaby O, Michalek J. Same or not the same? Comparison of adipose tissue-derived versus bone marrow-derived mesenchymal stem and stromal cells. Stem Cells Dev. 2012;21(14):2724-52.

11. Di Rocco G, lachininoto MG, Tritarelli A, Straino S, Zacheo A, Germani A, Crea F, Capogrossi MC. Myogenic potential of adipose-tissue-derived cells. J Cell Sci. 2006;119(Pt 14):2945-52.

12. Kesireddy V. Evaluation of adipose-derived stem cells for tissue-engineered muscle repair construct-mediated repair of a murine model of volumetric muscle loss injury. Int J Nanomedicine. 2016;11:1461-73.

13. Lawson MA, Purslow PP. Differentiation of myoblasts in serum-free media: effects of modified media are cell line-specific. Cells Tissues Organs. 2000; 167(2-3):130-7.

14. Dennis RG, Kosnik PE 2nd, Gilbert ME, Faulkner JA. Excitability and contractility of skeletal muscle engineered from primary cultures and cell lines. Am. J. Physiol. Cell Physiol. 2001;280(2):C288-95.

15. Saini A, Rullman E, Lilja M, Mandic M, Melin M, Olsson K, Gustafsson T. Asymmetric cellular responses in primary human myoblasts using sera of different origin and specification. PLoS One. 2018;13(2):e0192384.

16. Fujita $H$, Endo A, Shimizu K, Nagamori E. Evaluation of serum-free differentiation conditions for C2C12 myoblast cells assessed as to active tension generation capability. Biotechnol Bioeng. 2010;107(5):894-901.

17. Gawlitta D, Boonen KJ, Oomens CW, Baaijens FP, Bouten CV. The influence of serum-free culture conditions on skeletal muscle differentiation in a tissue-engineered model. Tissue Eng A. 2008;14(1):161-71.

18. Jana S, Leung M, Chang J, Zhang M. Effect of nano- and micro-scale topological features on alignment of muscle cells and commitment of myogenic differentiation. Biofabrication. 2014;6(3):035012.

19. Guex AG, Kocher FM, Fortunato G, Korner E, Hegemann D, Carrel TP, Tevaearai $H T$, Giraud MN. Fine-tuning of substrate architecture and surface chemistry promotes muscle tissue development. Acta Biomater. 2012;8(4):1481-9.

20. Beier JP, Klumpp D, Rudisile M, Dersch R, Wendorff JH, Bleiziffer O, Arkudas A, Polykandriotis E, Horch RE, Kneser U. Collagen matrices from sponge to nano: new perspectives for tissue engineering of skeletal muscle. BMC Biotechnol. 2009;9:34.

21. Dippold D, Cai A, Hardt M, Boccaccini AR, Horch R, Beier JP, Schubert DW. Novel approach towards aligned PCL-collagen nanofibrous constructs from a benign solvent system. Mater Sci Eng C Mater Biol Appl. 2017:72:278-83.

22. Bertram U, Steiner D, Poppitz B, Dippold D, Kohn K, Beier JP, Detsch R, Boccaccini AR, Schubert DW, Horch RE, et al. Vascular tissue engineering: effects of integrating collagen into a PCL based nanofiber material. Biomed Res Int. 2017;2017:9616939.

23. McAleer CW, Rumsey JW, Stancescu M, Hickman JJ. Functional myotube formation from adult rat satellite cells in a defined serum-free system. Biotechnol Prog. 2015;31(4):997-1003.

24. Das M, Rumsey JW, Bhargava N, Gregory C, Reidel L, Kang JF, Hickman JJ. Developing a novel serum-free cell culture model of skeletal muscle differentiation by systematically studying the role of different growth factors in myotube formation. In Vitro Cell. Dev. Biol. Anim. 2009;45(7):378-87.

25. Seo E, Kang H, Lim OK, Jun HS. Supplementation with IL-6 and Muscle Cell Culture Conditioned Media Enhances Myogenic Differentiation of Adipose Tissue-Derived Stem Cells through STAT3 Activation. Int J Mol Sci. 2018; 19(6). https://doi.org/10.3390/ijms19061557.

26. Stern-Straeter J, Bonaterra GA, Juritz S, Birk R, Goessler UR, Bieback K, Bugert P, Schultz J, Hormann K, Kinscherf R, et al. Evaluation of the effects of different culture media on the myogenic differentiation potential of adipose tissue- or bone marrow-derived human mesenchymal stem cells. Int J Mol Med. 2014;33(1):160-70.

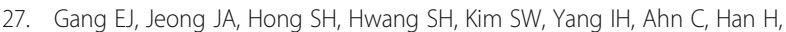
Kim H. Skeletal myogenic differentiation of mesenchymal stem cells isolated from human umbilical cord blood. Stem Cells. 2004;22(4):617-24.

28. Ansari S, Chen C, Xu X, Annabi N, Zadeh HH, Wu BM, Khademhosseini A, Shi $S$, Moshaverinia A. Muscle tissue engineering using gingival mesenchymal stem cells encapsulated in alginate hydrogels containing multiple growth factors. Ann Biomed Eng. 2016;44(6):1908-20.

29. Jiwlawat S, Lynch E, Glaser J, Smit-Oistad I, Jeffrey J, Van Dyke JM, Suzuki M. Differentiation and sarcomere formation in skeletal myocytes directly prepared from human induced pluripotent stem cells using a sphere-based culture. Differentiation. 2017;96:70-81. 
30. Andersen Jl, Juhl M, Nielsen T, Emmersen J, Fink T, Zachar V, Pennisi CP. Uniaxial cyclic strain enhances adipose-derived stem cell fusion with skeletal myocytes. Biochem Biophys Res Commun. 2014;450(2):1083-8.

31. Sassoli C, Vallone L, Tani A, Chellini F, Nosi D, Zecchi-Orlandini S. Combined use of bone marrow-derived mesenchymal stromal cells (BM-MSCs) and platelet rich plasma (PRP) stimulates proliferation and differentiation of myoblasts in vitro: new therapeutic perspectives for skeletal muscle repair/ regeneration. Cell Tissue Res. 2018;372(3):549-70.

32. van Steenberghe M, Schubert T, Guiot $Y$, Goebbels RM, Gianello P. Improvement of mesh recolonization in abdominal wall reconstruction with adipose vs. bone marrow mesenchymal stem cells in a rodent model. J Pediatr Surg. 2017;52(8):1355-62.

33. Fujita H, Shimizu K, Nagamori E. Novel method for fabrication of skeletal muscle construct from the C2C12 myoblast cell line using serum-free medium AIM-V. Biotechnol Bioeng. 2009;103(5):1034-41.

34. Ren L, Pan S, Li H, Li Y, He L, Zhang S, Che J, Niu Y. Effects of aspirin-loaded graphene oxide coating of a titanium surface on proliferation and osteogenic differentiation of MC3T3-E1 cells. Sci Rep. 2018;8(1):15143.

35. Lutter AH, Scholka J, Richter H, Anderer U. Applying XTT, WST-1, and WST-8 to human chondrocytes: a comparison of membrane-impermeable tetrazolium salts in 2D and 3D cultures. Clin Hemorheol Microcirc. 2017; 67(3-4):327-42.

36. Cheng G, Li Z, Wan Q, Yang R, Lv K, Li Z. Effects of a novel inoculation method on cell distribution, mineralization, and vascularization of tissueengineered constructs. Adv. Wound Care. 2016;5(3):89-101.

37. Mohamed-Ahmed S, Fristad I, Lie SA, Suliman S, Mustafa K, Vindenes H, Idris SB. Adipose-derived and bone marrow mesenchymal stem cells: a donormatched comparison. Stem Cell Res Ther. 2018;9(1):168

38. Gharaibeh B, Lu A, Tebbets J, Zheng B, Feduska J, Crisan M, Peault B, Cummins J, Huard J. Isolation of a slowly adhering cell fraction containing stem cells from murine skeletal muscle by the preplate technique. Nat Protoc. 2008;3(9):1501-9.

39. Lange C, Togel F, Ittrich H, Clayton F, Nolte-Ernsting C, Zander AR, Westenfelder C. Administered mesenchymal stem cells enhance recovery from ischemia/reperfusion-induced acute renal failure in rats. Kidney Int. 2005;68(4):1613-7.

40. Togel F, Hu Z, Weiss K, Isaac J, Lange C, Westenfelder C. Administered mesenchymal stem cells protect against ischemic acute renal failure through differentiation-independent mechanisms. Am. J. Physiol. Renal Physiol. 2005;289(1):F31-42.

Ready to submit your research? Choose BMC and benefit from:

- fast, convenient online submission

- thorough peer review by experienced researchers in your field

- rapid publication on acceptance

- support for research data, including large and complex data types

- gold Open Access which fosters wider collaboration and increased citations

- maximum visibility for your research: over $100 \mathrm{M}$ website views per year

At $\mathrm{BMC}$, research is always in progress.

Learn more biomedcentral.com/submissions 